\title{
Intravenous leiomyomatosis with extension to the heart: Rare or underestimated?
}

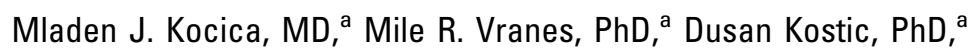

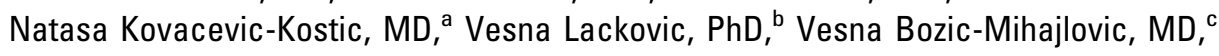
Milos M. Velinovic, PhD, ${ }^{a}$ Aleksandar Dj. Mikic, MD, and Nevena Dimitrijevic-Kalezic, PhD, ${ }^{d}$ Serbia and Montenegro

I ntracardiac leiomyomatosis (ICL) is a rare and dangerous form of intravenous leiomyomatosis (IVL) ${ }^{1-5}$ The case of ICL presented here depicts some diagnostic and surgical difficulties that may arise from the rarity and complexity of this condition. Further, to our best knowledge, neither the mass nor the growth rate of the abdominal part of the presented ICL has been described in the available literature. Finally, this case and extensive literature search allowed us to clarify some important questions pertaining to this entity.

\section{Clinical Summary}

A 36-year-old white woman (multigravid, biparous), who underwent a right salpingo-oophorectomy 7 years before admission, presented with a recurrent growing pelvic mass, dyspnea, fatigue, weight loss, ascites, leg swelling, and dysmenorrhea.

Abdominal and pelvic ultrasound revealed a right-sided, uterine adnexal tumor $(5 \times 11 \mathrm{~cm})$ penetrating the inferior vena cava (IVC) (Figure 1,a). After a clinical episode of severe dyspnea, tachycardia, and syncope, echocardiography revealed the presence of a mass in the right atrium, originating from the IVC and protruding across the tricuspid valve throughout the cardiac cycle. The patient was transferred for "palliative" cardiac surgery with a presumptive diagnosis of recurrent ovarian malignancy with intracardiac extension.

Repeat abdominal ultrasound revealed tumor-free left iliac and femoral veins, so this route was used, in addition to the superior vena cava, for optimal venous drainage during cardiopulmonary bypass (CPB). On beating heart right atriotomy, a solid, molding tumor $(250 \mathrm{~g}, 20 \times 4 \mathrm{~cm})$ was easily removed from the right heart chambers by slight traction. A conically shaped IVC portion was sharply excised at an accessible and safe distance. Weaning from $\mathrm{CPB}$ and the rest of procedure were uneventful.

\footnotetext{
From the Institute for Cardiovascular Diseases, ${ }^{\mathrm{a}}$ Institute for Histology and Embryology ${ }^{\mathrm{b}}$ Institute for Pathology, ${ }^{\mathrm{c}}$ and Institute for Enocrinology, ${ }^{\mathrm{d}} \mathrm{UC}$ Clinical Centre of Serbia, Serbia and Montenegro.

Received for publication Aug 16, 2005; accepted for publication Aug 22, 2005.

Address for reprints: Mladen J. Kocica, MD, UC Clinical Centre of Serbia, Institute for Cardiovascular Diseases, Clinic for Cardiac Surgery, 8th Kosta Todorovic St, 11000 Belgrade, Serbia and Montenegro (E-mail: kocica@sezampro.yu).

J Thorac Cardiovasc Surg 2005;130:1724-6

$0022-5223 / \$ 30.00$

Copyright $\odot 2005$ by The American Association for Thoracic Surgery doi:10.1016/j.jtcvs.2005.08.021
}

Standard and immunohistochemical analyses (Figure 1, $b-d$ ) indicated IVL. Histologic diagnosis was confirmed using international teleconsultation facilities (Department of Pathology, Thoraxklinik, Heidelberg, Germany).
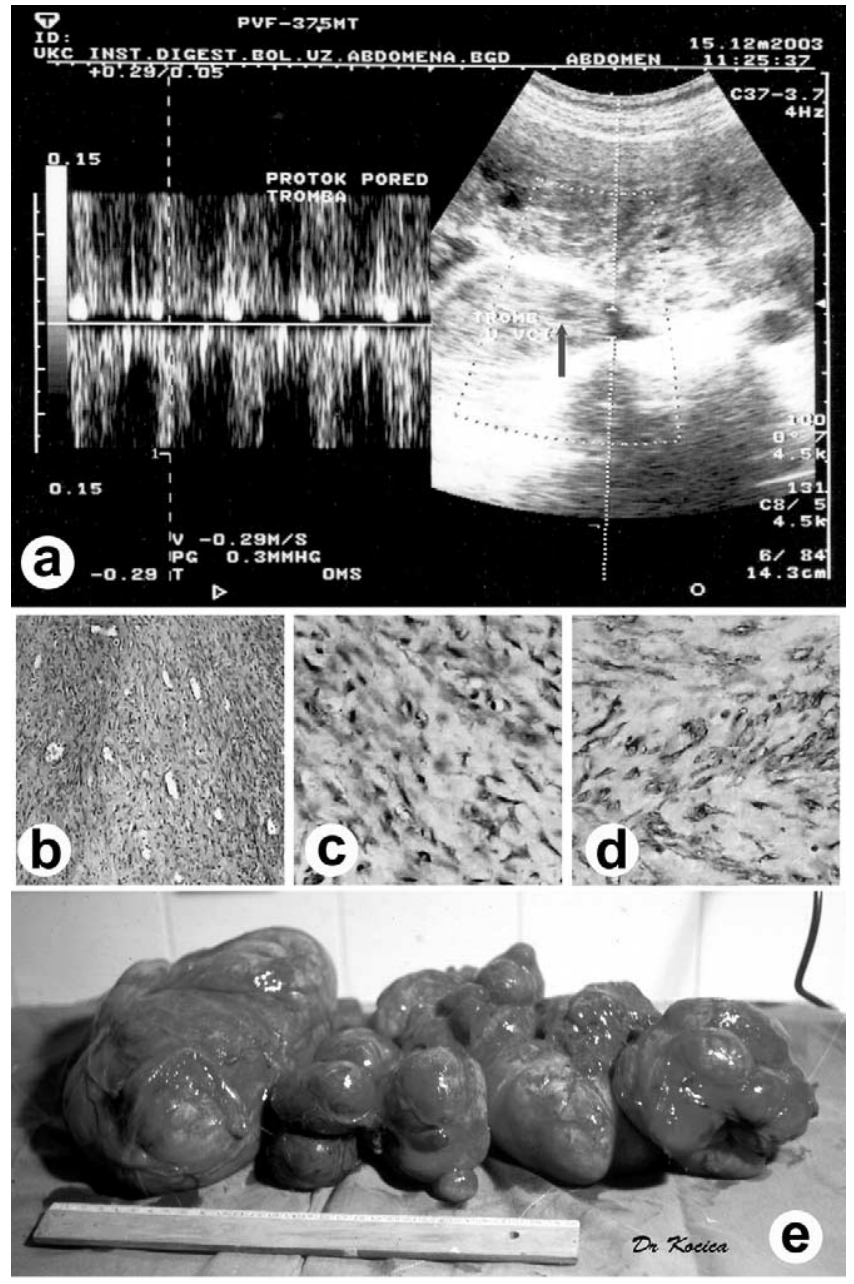

Figure 1. a, Abdominal ultrasound revealing presence of tumor in IVC (arrow). Doppler signals indicated incomplete caval obstruction. b, ICL: hematoxylin-eosin $16 \times 10$; c, ICL: myoglobin,$+ 25 \times$ 10; d, ICL: desmin +, $25 \times 10$; e, IVL: giant tumor mass $(8.5 \mathrm{~kg}, 45$ $\times 20 \times 20 \mathrm{~cm}$ ) excised at abdominal stage operation. 
TABLE 1. Intracardiac leiomyomatosis: Review of the literature

\begin{tabular}{|c|c|c|c|c|}
\hline \multicolumn{5}{|c|}{ Cases reported after 2003} \\
\hline No. & Reference & C/A & ICL & Surgery \\
\hline 1 & Kocica et al. 2005 (current report) & $1 / 36$ & RV & Two-stage \\
\hline 2 & Ozer et al. Echocardiography. 2005;22:514-16 & $1 / 43$ & RA & Two-stage \\
\hline 3 & Thukkani et al. Ann Thorac Surg. 2005;79:707-9 & $1 / 36$ & RV & Two-stage \\
\hline 4 & Moorjani et al. J Card Surg. 2005;20:382-5 & $1 / 64$ & RV & One-stage \\
\hline 5 & Murphy et al. EJVES Extra. 2005;9:4-6 & $1 / 49$ & RA & One-stage \\
\hline 6 & Bennett et al. Nat Clin Pract Cardiovasc. Med 2005;2:369-72 & $1 / 58$ & RV & One-stage \\
\hline 7 & DeRubertis et al. J Vasc Surg. $2004 ; 40: 554-8$ & $1 / 45$ & RA & Two-stage, EVS \\
\hline 8 & Topcuoglu et al.Ann Thorac Surg. 2004;78:330-2 & $1 / 58$ & RV & Two-stage \\
\hline 9 & Uchida et al. Obstet Gynecol. 2004;103:1068-70 & $1 / 53$ & RV & One-stage \\
\hline 10 & Feng et al. Chin Med Sci J. 2004;19:55. & $1 / 38$ & RA & Two-stage \\
\hline 11 & Nishizawa et al. J Am Coll Surg. 2004;198:842-3 & $1 / 51$ & RA & One-stage, VATS, CPB \\
\hline 12 & Sakamoto et al. Jpn J Thorac Cardiovasc Surg. 2004;52:148-51 & $1 / 72$ & RV & One-stage \\
\hline 13 & Jerez-Anera et al. Rev Esp Anestesiol Reanim. 2004;51:40-3 & $1 / 61$ & RA & One-stage \\
\hline 14 & Sasaki et al. Nippon Naika Gakkai Zasshi. 2004;93:142-4 & $1 / 72$ & RA & One-stage \\
\hline 15 & Lam et al. J Vasc Surg. 2004;39:465-9 & $2 / 41,47$ & RA & Two-stage \\
\hline 16 & Saitoh et al. Gynecol Obstet Invest. 2004;58:168-70 & $1 / \mathrm{NA}$ & RA & One-stage \\
\hline 17 & Burke et al. Pathology. 2004;36:202-3 & $1 / 47$ & PA & Death before surgery \\
\hline \multirow{3}{*}{\multicolumn{2}{|c|}{ Total number of cases }} & $18 / 51(36-72)$ & $\mathrm{RA}-10$ & None $1(4.4 \%)$ \\
\hline & & & \multirow{2}{*}{$\begin{array}{l}\text { RV }-7 \\
\text { PA }-1\end{array}$} & One-stage $9(27.9 \%)$ \\
\hline & & & & Two-stage $8(42.7 \%)$ \\
\hline \multicolumn{5}{|c|}{ Cases reported before $2003^{*}$} \\
\hline No. & Reference & C/A (m) & ICL & Surgery \\
\hline \multirow[t]{4}{*}{1} & Lam et al. ${ }^{4}$ Review of cases with intracardiac extension between & $68 / 47(26-76)$ & $\mathrm{RA}-31$ & None $3(4.4 \%)$ \\
\hline & 1900 and 2003 & & $\mathrm{RV}-31$ & Incomplete excision $17(25.0 \%)$ \\
\hline & & & $P A-6$ & One-stage $19(27.9 \%)$ \\
\hline & & & & Two-stage $29(42.7 \%)$ \\
\hline \multirow[t]{3}{*}{2} & Nam et al. ${ }^{3}$ Review of cases with intracardiac extension between & $16 / 50(26-72)$ & $\mathrm{RA}-7$ & Incomplete excision 2 (12.5\%) \\
\hline & & & $\mathrm{RV}-9$ & One-stage $5(33.3 \%)$ \\
\hline & & & & Two-stage $9(56.2 \%)$ \\
\hline \multirow[t]{4}{*}{3} & Harris and Karakousis ${ }^{2}$ Review of cases with intracardiac extension & $34 / 48(26-72)$ & $\mathrm{RA}-12$ & Incomplete excision $6(17.6 \%)$ \\
\hline & & & RV -22 & One-stage $9(26.5 \%)$ \\
\hline & & & & Two-stage $15(44.1 \%)$ \\
\hline & & & & NA $4(11.8 \%)$ \\
\hline \multirow[t]{3}{*}{4} & Iverson et al. ${ }^{1}$ Review of cases with intracardiac extension up to 1983 & 6/NA & NA & Incomplete excision 2 (33.3\%) \\
\hline & & & & Two-stage $1(16.7 \%)$ \\
\hline & & & & NA $3(50.0 \%)$ \\
\hline \multicolumn{2}{|c|}{ Total number of cases* } & $95 / 48(26-76)$ & $\mathrm{RA}-35$ & None $3(3.1 \%)$ \\
\hline & & & $\mathrm{RV}-48$ & Incomplete excision $20(21.1 \%)$ \\
\hline & & & $P A-6$ & One-stage $24(25.3 \%)$ \\
\hline & & & $N A-6$ & Two-stage $41(43.1 \%)$ \\
\hline & & & & NA $7(7.4 \%)$ \\
\hline \multicolumn{5}{|c|}{ Cumulative data* } \\
\hline \multirow{5}{*}{\multicolumn{2}{|c|}{ Total number of cases up to $2005^{*}$}} & $113 / 49.5(26-76)$ & $\mathrm{RA}-45$ & None $4(3.5 \%)$ \\
\hline & & & $\mathrm{RV}-55$ & Incomplete excision $20(17.7 \%)$ \\
\hline & & & $P A-7$ & One-stage $33(29.2 \%)$ \\
\hline & & & $N A-6$ & Two-stage $49(43.4 \%)$ \\
\hline & & & NA & $7(6.2 \%)$ \\
\hline
\end{tabular}

$I C L$, Intracardiac leiomyomatosis; $C / A$, cases/age; $(m)$, mean age (age range in parentheses); $R A$, right atrium; $R V$, right ventricle; $P A$, pulmonary artery; $E V S$, endovascular surgery; VATS, video-assisted thoracoscopic surgery; $C P B$, cardiopulmonary bypass; $N A$, not available. *Identical reports from References $1,2,3$, and 4 were counted as 1 in total score. 
A second-stage operation was scheduled to remove abdominal and intracaval tumor remnants. During 1 month, between 2 operations, the abdominal mass doubled in size, resembling terminal gravidity, without any other clinical worsening in the patient's condition except increased leg swelling.

On median laparotomy, the right colon and small bowel were mobilized and Kocherization of duodenum was performed to gain safe access to the IVC. Vessel loops were placed around the IVC below the renal veins and inferiorly, below the orifice of the right ovarian vein. After blunt mobilization of the retroperitoneal mass, elliptical excision of the IVC around the right ovarian vein orifice allowed traction delivery of the intracaval portion of the tumor. The IVC was closed with linear suture. The entire tumor $(8.5 \mathrm{~kg}, 45 \times 20$ $\times 20 \mathrm{~cm}$ ) and the uterus were removed en bloc (Figure 1,d).

The patient's postoperative course was complicated with excessive bleeding, and relaparotomy was necessary. Hemostatic sutures were placed on the uterine cervical stump, and control of the bleeding site was fully accomplished.

The rest of the postoperative course was uneventful. Control abdominal ultrasonography and echocardiography revealed no visible intravascular tumor remnants. Nine months after the patient's discharge, no recidivant or metastatic masses were detected by ultrasonography.

\section{Discussion}

Since the first description of ICL by Durck and Hormann in 1907, 113 cases have been published. ${ }^{2,3}$ Before 1980, when Timmis and colleagues extracted an ICL, ${ }^{2}$ all attempts to do so were fatal. A new era in treatment of IVL and ICL began in 1982, when Ariza and colleagues performed the first successful 2-stage total resection. ${ }^{2}$

We performed a comprehensive literature search, including all available electronic and paper sources, together with the references in each publication, to identify all reported cases of ICL. A compendium of information from isolated reports is summarized in Table 1. We believe that ICL is not so rare an entity as previously thought (during the past 2 years, $16 \%$ of all ICL cases were reported). A higher index of clinical suspicion with the availability of contempory imaging tools (ie, abdominal and car- diac ultrasound, computed tomography, magnetic resonance imaging, and venography) will lead to an increased number of reports in the future. ${ }^{2-5}$

IVL and ICL are benign (estrogen sensitive?) intravascular proliferations of smooth muscle cells arising from the uterine vein wall or the myometrium (ie, uterine leiomyoma). The tumor has the potential to grow inside the veins of broad ligament, extending to the IVC through different routes (ie, iliac veins and ovarian veins), reaching up to the right heart chambers and occasionally the pulmonary artery. ${ }^{1-5}$

Because a complete removal of the tumor is mandatory, ${ }^{1-5}$ an adequate preoperative diagnosis should provide detailed information about the tumor localization, extravascular and intravascular diameters, site of vascular entry, and patency of iliac and femoral veins. $^{5}$

The optimum and safest strategy is a single or 2-stage procedure with an abdominal approach and subsequent thoracic approach. The abdominal stage should ensure complete extravascular tumor excision and control of the vascular entry site(s). The thoracic stage, preferably with short total CPB on the beating heart, should allow easy tumor withdrawal from the right cardiac chambers and IVC. ${ }^{1-5}$

\section{References}

1. Iverson LIG, Lee J, Drew D, Sharp J, Ecker RR, Young JN, et al. Intravenous leiomyomatosis with cardiac extension. Tex Heart Inst J. 1983;10:275-8.

2. Harris LM, Karakousis CP. Intravenous leiomyomatosis with cardiac extension: tumor thrombectomy through an abdominal approach. $J$ Vasc Surg. 2000;31:1046-51.

3. Nam MS, Jeon MJ, Kim YE, Kim JW, Park KH, Hong YS. Pelvic leiomyomatosis with intracaval and intracardiac extension: a case report and review of the literature. Gynecol Oncol. 2003;89:175-80.

4. Lam PM, Lo KWK, Yu MY, Wong WS, Lau JYW, Arifi AA, et al. Intravenous leiomyomatosis with atypical histologic features: a case report. Int J Gynecol Cancer. 2003;13:83-7.

5. Roques F, Sanchez B, Bucher B, Lariviere J. Role of pre-operative assessment in the surgical management of leiomyoma extended to the right heart chambers: a compendium of information from isolated reports. Eur J Cardiothorac Surg. 2001;19:522-4. 